\title{
Interface between Lithium Metal and Garnet Electrolyte: Recent Progress and Perspective
}

\author{
Jin Wang ${ }^{+},{ }^{[a, b]}$ Gang Huang ${ }^{+},{ }^{[c]}$ and Xin-Bo Zhang*[a]

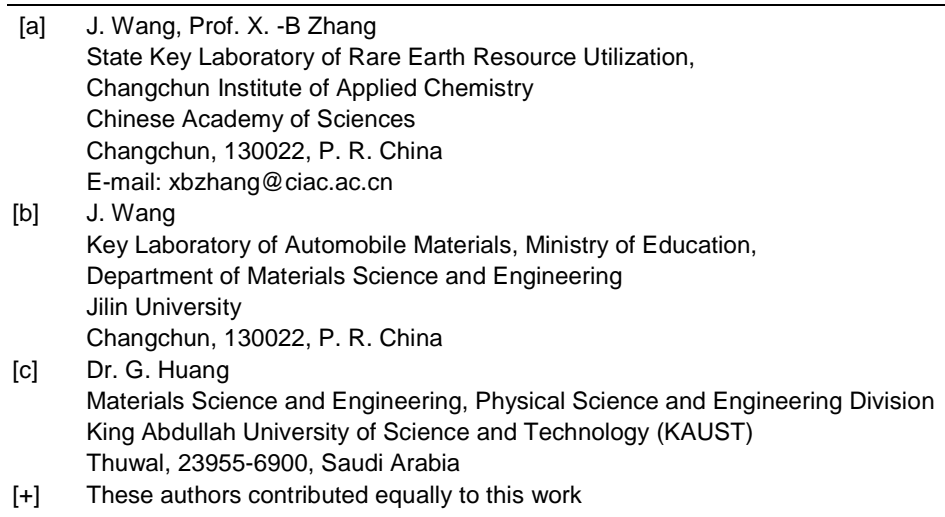

1 Abstract: Garnet electrolytes (GEs) with high ion conductivity, 6

2 excellent stability against lithium metal (LM) as well as wide 7

3 electrochemical potential window are attracting increasing interest as8

4 they have the potential to enable all-solid-state Li metal batteries 9

5 (ASSLMBs). However, GEs-based ASSLMBs deeply suffer froł0

6 daunting problems such as high resistance, fast short circuit and rapil 1

7 performance degradation, which can be largely attributed 2

8 unsatisfactory LM/GE interface. To this end, this minireview focus $\$ 3$

9 on the LM/GE interface by summarizing the main challenges

10 comprehensively, recapitulating emerging strategies for these

11 challenges, and providing perspectives for future research.

\section{1. Introduction}

With the explosive boom in the fields of portable electronics and electric vehicles, lithium-ion batteries (LIBs) have achieved remarkable success in the market. Conventional LIBs normally consist of carbon anodes, flammable organic electrolytes (OEs) and Li-containing oxides, challenging with unsatisfied energy density and poor safety. To further boost the energy density, lithium metal (LM) has been widely deemed as an ultimate anode candidate due to its highest theoretical specific capacity (3860 $\mathrm{mAh} / \mathrm{g}$, more than 10 times of the current commercial carbon anodes) and lowest electrochemical potential (-3.04 V versus standard hydrogen electrode). However, the uncontrollable dendrite growth of LM during cycling can give rise to serious security risks, impeding its successful use in LIBs. ${ }^{[1]}$ Replacing the OEs with solid-state electrolytes (SSEs) and naturally building allsolid-state $\mathrm{Li}$ metal batteries (ASSLMBs) are promising to completely address the fire and dendrite issues of LM-based batteries because SSEs possess non-flammability and high mechanical strength. ${ }^{[2]}$ In this regard, ASSLMBs are on the cusp of being the most appealing next-generation energy storage systems.

Generally, SSEs used in ASSLMBs mainly belong to two groups: polymer electrolytes (PEs) and inorganic electrolytes (IEs). ${ }^{[3]}$ PEs are flexible and processable, and meanwhile hold good wetting ability toward electrodes. However, the development of PEs-based ASSLMBs has been limited by the poor roomtemperature ion conductivity of PEs. ${ }^{[4]}$ In contrast, IEs possess satisfactory ion conductivity, outstanding thermal stability as well as high Young's modulus. Among various IEs, garnet electrolytes (GEs) are being actively investigated owing to their high roomtemperature ion conductivity $\left(10^{-3} \mathrm{~S} / \mathrm{cm}\right)$, excellent stability against $L M$ and wide electrochemical potential window since

Jin Wang received her B.S. degree in materials science and engineering from Changchun University of Science and Technology in 2015. She is currently pursuing a Ph.D. in materials science at Jilin University of China. Her current interests include design and synthesis of solid-state electrolytes for lithium-air batteries and $\mathrm{Li}$ metal protection.

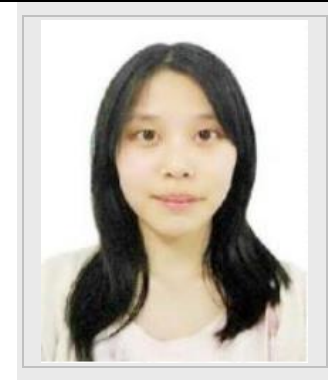

Gang Huang received his $\mathrm{PhD}$ in applied chemistry from Changchun Institute of Applied Chemistry (CIAC) in 2016. Now he works at King Abdullah University of Science and Technology (KAUST) as a post-doctoral fellow and his research focuses on the development and characterization of nanoporous materials for $\mathrm{Li}$-ion and $\mathrm{Li}-\mathrm{O}_{2}$ batteries.

Xin-Bo Zhang is a full professor at Changchun Institute of Applied Chemistry (CIAC), Chinese Academy of Sciences (CAS). He obtained his Ph.D. degree in inorganic chemistry from CIAC. His interests mainly focus on functional inorganic materials for batteries, fuel cells, and electrochemical catalysis.

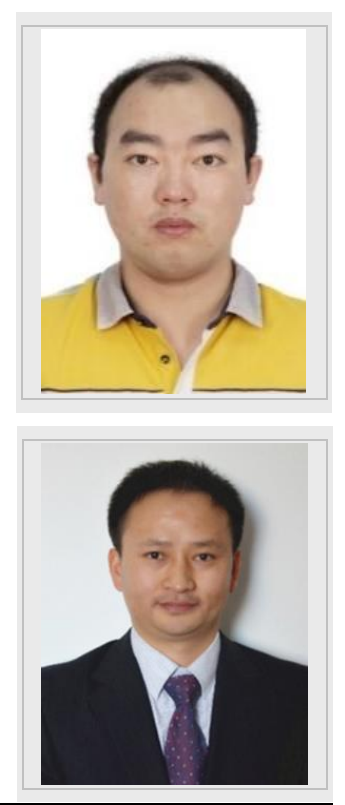


1 Weppner's group originally reported the cubic phase $\mathrm{Li}_{7} \mathrm{La}_{3} \mathrm{Zr}_{2} \mathrm{O}_{3} 6$

2 (LLZO). ${ }^{[5]}$ Following this discovery, massive attempts to dope7

3 cations and optimize sintering process are motivated by concern $\$ 8$

4 of fast ionic conduction. ${ }^{[6]}$ Although the ion conductivities of GE39

5 from these methods are comparable to OEs, the interfacialO

6 resistances are too large to enable GEs-based ASSLMB 1

7 competitive to commercial LIBs. ${ }^{[7]}$ Moreover, fast short circuits \& 2

8 the GEs-based ASSLMBs can sometimes be induced by the3

9 daunting $\mathrm{Li}$ dendrite issue, which is closely related to th

10 properties of LM/GE interface. ${ }^{[8]}$ Therefore, the LM/GE interfact5

11 plays vital roles in the electrochemical performance of GE\$6

12 based ASSLMBs. Understanding and improving the interfact7

13 between LM and GE are of importance for enhancing the overat8

14 cell performance.

In this minireview, we firstly summary the main challenges of 0

$16 \mathrm{LM} / \mathrm{GE}$ interface, including large interfacial resistance and1

17 uncontrollable $\mathrm{Li}$ dendrite growth, followed by systematical5/2

18 discussing the recent advances in improving LM/GE interface. 3

19 Among the various strategies, removal of $\mathrm{Li}_{2} \mathrm{CO}_{3}$, the introduction 4

20 of alloy or soft interlayers, design of metal anodes, and change 55

21 of the physical and chemical properties of GEs are underscored6

22 (Figure 1). Finally, general conclusions of current limitations and7

23 perspectives for recommended future research directions a 58

24 presented.

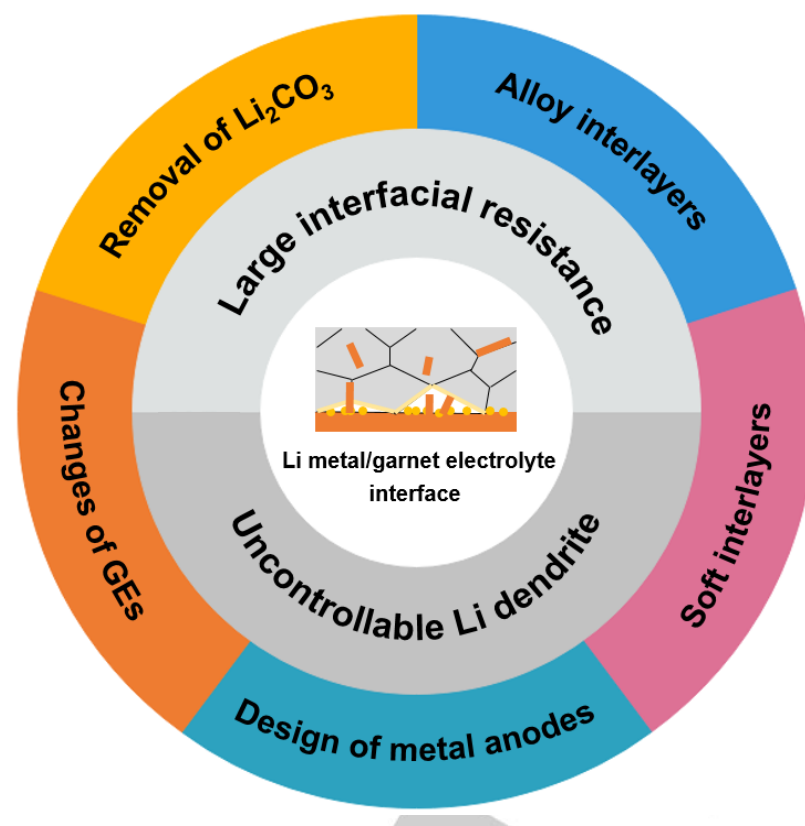

26 Figure 1. An overview of LM/GE interface, including its challenges are responding strategies.

\section{2. Challenging Issues at LM/GE Interface}

\section{2.1. Large Interfacial Resistance}

30 High electrochemical/chemical stability is one of the reasons $f \theta 1$

31 the popularity of GEs. However, Han et al. revealed that th\&2

32 intrinsic electrochemical stability window of LLZO was 0.05-2.91

$33 \mathrm{~V}$ (Figure 2a), which was smaller than the previously reported

34 value of $0-6$ V. ${ }^{[9]}$ Moreover, first-principle calculation and

35 experimental results confirmed that LLZO might be reduced into
$\mathrm{Zr}_{3} \mathrm{O}, \mathrm{Li}_{2} \mathrm{O}$ and $\mathrm{La}_{2} \mathrm{O}_{3}$ when contacting $\mathrm{LM}$, while the $\mathrm{Zr}_{3} \mathrm{O}$ could be further reduced into $\mathrm{Zr}$ metal. Most of these reduction products are poor ionic conductors, causing high interfacial resistance. Zhu and co-workers also observed measurable LM induced reduction of $\mathrm{Zr}^{4+}$ in $\mathrm{Ta} / \mathrm{Nb} / \mathrm{Al}$ doped LLZO samples (denoted as LLZTO (or LLZT)/LLZNO/LALZO). ${ }^{[10]}$ Besides the $\mathrm{Zr}^{4+}, \mathrm{Nb}^{5+}$ in LLZNO could also be significantly reduced. Therefore, the increasing interfacial resistance caused by GEs' limited electrochemical/chemical stability should be taken seriously.

Owing to the stiffness of GEs, heating has been widely adopted to achieve close contact between LM and GEs. Although first-principle calculation results indicate that the GE exhibit intrinsic lithiophilic property towards $\mathrm{LM}^{,{ }^{[11]}}$ poor wetting behavior will still occur even after heating the LM/GE interface, arousing large interfacial resistance. With the aid of spectroscopy studies, Doeff' group revealed that $\mathrm{Li}_{2} \mathrm{CO}_{3}$ contaminant was formed on the surface of GEs when they were exposed to air, which was regarded as the main origin of poor wettability towards LM. ${ }^{[12]}$ After simply removing the $\mathrm{Li}_{2} \mathrm{CO}_{3}$ by polishing, the wettability of the GEs surface was greatly enhanced, which further confirmed that $\mathrm{Li}_{2} \mathrm{CO}_{3}$ was indeed the fundamental reason for the lithiophobic surfaces of GEs. A widely accepted reaction for the formation of $\mathrm{Li}_{2} \mathrm{CO}_{3}$ was proposed by Sakamoto' group with the combination of experimental measurements and computational modeling. ${ }^{[13]}$ Figure $2 b$ illustrates the distribution of contaminant layers on the surface of LLZO. Firstly, $\mathrm{LiOH}$ forms through $\mathrm{Li}^{+} / \mathrm{H}^{+}$ etween $\mathrm{LZZO}$ and moisture. Carbonation of $\mathrm{LiOH}$ is quenened, generating $\mathrm{Li}_{2} \mathrm{CO}_{3}$ contaminant. 55 exposure the amount of $\mathrm{Li}_{2} \mathrm{CO}_{3}$ strongly depends on the 


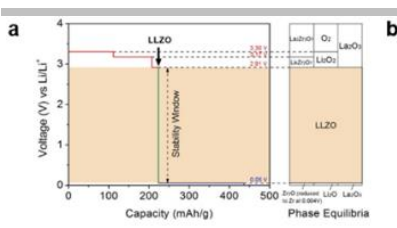

c
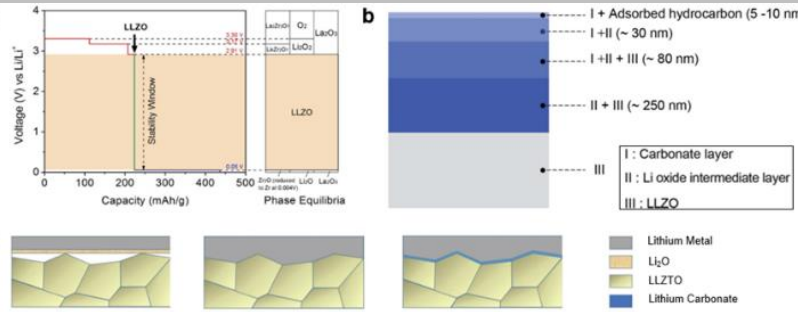
Lizto
Lizto

2 Figure 2. (a) First principles calculation results of the voltage profile of LLZ $Q$ upon lithiation and delithiation. ${ }^{[9]}$ (b) Schematic of the contamination layers 802 the surface of LLZO. Compositions and thickness of each layer were detected by XPS analysis. ${ }^{[13]}$ (c) Schematic of different wetting behaviors of LLZT83 surfaces with molten LM. ${ }^{[11]}$

\section{2.2. Uncontrollable Li Dendrite}

8 Newman et al. held a view that the Li dendrite could be eliminate 69

9 when the shear modulus of electrolyte was more than twice th $\mathrm{Ht}_{\mathrm{t}} \mathrm{O}$

10 of LM (3.4 GPa). ${ }^{[17]}$ But this guideline only works to LM/PZ1

11 interface, not to LM/GE interface. Numerous reports have2

12 observed that $\mathrm{Li}$ dendrite forms easily and penetrates GE fa3t3

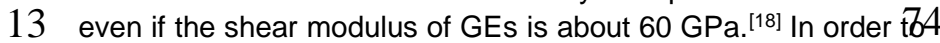

14 accurately describe the ability of SSEs in terms of suppressing Zi5

15 dendrite growth, a concept of "critical current density (CCD)" has6

16 been proposed, which stands for maximum current density that 7

17 SSEs can withstand before short circuit. To date, the CCD of the

18 GEs is only around $0.5 \mathrm{~mA} / \mathrm{cm}^{2}$, far from the goal of $3-109$

$19 \mathrm{~mA} / \mathrm{cm}^{2}$.[3]

The poor contact between $\mathrm{LM}$ and GE makes $\mathrm{Li}^{+}$ion 1 concentrate at the confined contact points of the Li/GE interface 2 (Figure 3a), resulting in inhomogeneous distribution of $\mathrm{Li}^{+}$ions. Consequently, dendrite forms at these "hot spots". ${ }^{[19]}$ In addition, Li stripping may produce new voids at the LM surface if the dissolved Li cannot be replenished in time. These new voids will further deteriorate the interface contact and accelerate the $\mathrm{Li}$ dendrite growth. Recently, Wang et al. proposed a new terminology named critical stack pressure to define the balance point where incoming Li flux from the applied stack pressure is equal to dissolving Li. ${ }^{[20]}$ Since the rate of $\mathrm{Li}$ replenishment is proportional to the adatom diffusion rate of $L M$ and the applied stack pressure can facilitate adatom diffusion, it is obvious that 3 the applied stack pressure should higher than the critical stack pressure to avoid new voids formation, as a result, increasing th\&4 CCD to some extent. ${ }^{[20-21]}$ Besides, power-law creep model an 85 experimental results presented that the $\mathrm{Li}$ adatom diffusion rat8 could be significantly improved even with a slight increase of 8 temperature. ${ }^{[22]}$ What's more, Krauskopf et al. revealed the 8 i9 adatom diffusion rate in Li-Mg alloy was much faster than in $\mathrm{LM}^{\left[{ }^{[22 b]}\right]}$ Therefore, enlarging pressure and increasing temperature, as well as using alloys are all instructive for maintaining intimato LM/GE interface contact and alleviating "hot spots".

In addition to these "hot spots", morphological flaws, such a1 cracks and ledges, on the GEs surface are also the suspicious location for Li dendrite formation (Figure 3b). ${ }^{[23]}$ Many group 2 have observed that whisker/sphere/cluster/filament-like 93 dendrite preferentially deposits on the surface flaws of the GEg4 through in-operando optical microscope. ${ }^{[23-24]}$ Under the stres 95 generated by dendrite penetration, new cracks appeared besid 6 the increase of crack length. ${ }^{[25]}$ Hence, crack and stress promoted each other until the crack penetrated across the GEs, resulting in short circuit.

Grain boundary is another passway for Li dendrite growth. ${ }^{[26]}$ Sakamoto et al. directly observed that the Li dendrite propagated intergranularly through the grain boundaries of GEs by SEM (Figure 3c). ${ }^{[27]}$ Molecular dynamics simulations revealed that shear modulus at grain boundaries was $50 \%$ lower than that at bulk regions. ${ }^{[19 c]}$ This remarkable softening in elastic properties is considered as the primary origin for Li deposition near grain boundaries. Inhomogeneous ionic conductivities between grain boundary and bulk region appear to be another possible reason. ${ }^{[28]}$ It is generally believed that the differences of composition at grain boundaries and grains cause inhomogeneous ionic conductivities. ${ }^{[29]}$ But Smetaczek et al. claimed that neither local Al content nor local Li content had an obvious correlation with the local ionic conductivity in LALZO. ${ }^{[30]}$ Maybe other factors have pronounced effects on the difference in ionic conductivity, which requires further study.

Instead of propagating from one electrode to another isolated $\mathrm{Li}$ dendrite within GE has been observed frequently (Figure 3d). ${ }^{[31]}$ Density functional theory (DFT) calculations demonstrated that $e^{-}$was thermodynamically favorable to be trapped by La atom in GE, which might cause LM to deposit directly inside the GE. ${ }^{[32]}$ Consistently, Janek's group presented fast $\mathrm{Li}$ nucleation inside the LLZO after $\mathrm{e}^{-}$injection. ${ }^{[23]}$ By comparing the growth behaviors of $\mathrm{Li}$ dendrite in LLZO, LiPON and $\mathrm{Li}_{3} \mathrm{PS}_{4}$, Han et al. found that the CCDs of electrolytes were proportional to their electronic conductivities. Evidently, the relatively high electronic conductivity of GE is strongly responsible for the fast Li dendrite growth inside GE.
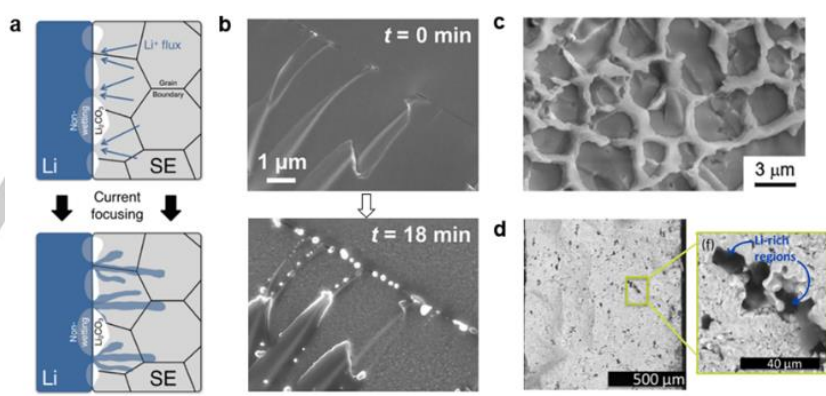

Figure 3. (a) Potential microstructural contributions to inhomogeneous $\mathrm{Li}$ deposition with concentrated $\mathrm{Li}^{+} .{ }^{[19 c]}$ (b) SEM images during $\mathrm{Li}$ deposition on LLZO cross-section with a current density of about $200 \mathrm{~mA} / \mathrm{cm}^{2}$ using electron beam. Preferred nucleation sites along cracks and ledges can be seen. ${ }^{[23]}$ (c) SEM image of the web-structure LM deposition along the grain boundaries in cycled GE. ${ }^{[27]}$ (d) SEM image of the cycled GE. ${ }^{[31 b]}$

\section{Strategies for Improving LM/GE Interface}

\subsection{Removal of $\mathrm{Li}_{2} \mathrm{CO}_{3}$}

Considering that the formation of $\mathrm{Li}_{2} \mathrm{CO}_{3}$ is almost inevitable during the storage of GEs, removal of the formed $\mathrm{Li}_{2} \mathrm{CO}_{3}$ is a practical solution for improving the LM/GE interface. Typical mechanical polishing has become a widely accepted pretreatment method, ${ }^{[12,33]}$ but it is insufficient to completely remove $\mathrm{Li}_{2} \mathrm{CO}_{3}$, meanwhile more flaws will be introduced on the electrolyte surface after polishing. Through reacting LLZT with 
1 carbon (LLZT-C) at $700{ }^{\circ} \mathrm{C}$ (Figure 4a), Li et al. successfuli5y 1

2 removed $\mathrm{Li}_{2} \mathrm{CO}_{3}$ and lowered the interfacial ASR to $28 \Omega / \mathrm{cm}^{2} .{ }^{2} 352$

3 In a later work, Cheng et al. claimed that the $\mathrm{Li}_{2} \mathrm{CO}_{3}$-contaminate 513

4 GEs could be recovered after heating at $250{ }^{\circ} \mathrm{C}$ under ine5t4

5 atmosphere. ${ }^{[35]}$ These conventional thermal treatments a $\$ 5$

6 generally time-consuming, and potential to generate impurify6

7 phase due to the high-temperature induced Li loss. Reducing th $₫ 7$

8 thermal treatment temperature is the future development direction 8

9 in this field. For avoiding thermal treatment, Sun' group proposed 9

10 rapid $\mathrm{HCl}$ treatment to remove the surface $\mathrm{Li}_{2} \mathrm{CO}_{3}$ of LLZTO with 60

11 one minute (Figure 4b). ${ }^{[36]}$ This method could also be extended 61

12 other acids, such as $\mathrm{H}_{2} \mathrm{SO}_{4}$ and $\mathrm{H}_{3} \mathrm{PO}_{4}$. Interestingly, $\mathrm{H}_{3} \mathrm{PO}_{4}$ cd 2

13 not only remove contaminants, but also generate $\mathrm{Li}_{3} \mathrm{PO}_{4}$ layer. ${ }^{1} 63$

$14 \mathrm{This}^{\mathrm{Li}} \mathrm{PO}_{4}$ layer converts the surface of GE from lithiophobic 64

15 lithiophilic, leading to a dramatically reduced interfacial ASR of $\varnothing 5$

$16 \Omega / \mathrm{cm}^{2}$. Moreover, $\mathrm{Li}_{3} \mathrm{PO}_{4}$ is capable of inhibiting $\mathrm{Li}$ dendrif6

17 penetration, boosting the battery performance significantl 67

18 Although acid treatment is facile and fast, it is still hard to remove8

19 all the $\mathrm{Li}_{2} \mathrm{CO}_{3}$, especially the one inside the GEs. Thus, it is most

20 important to increase the intrinsic air stability of GEs.
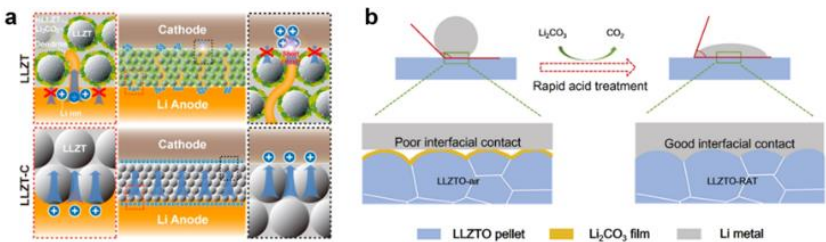

= UzTO pellet $=\mathrm{L}_{2} \mathrm{CO}_{3}$ film $=$ umetal

Figure 4. (a) Schematic of ASSLMBs with LLZT and LLZT-C. ${ }^{[34]}$ (b) Schematic illustration of Li/LLZTO interface before and after the rapid acid treatment. ${ }^{[36]}$

\section{3.2. Alloy Interlayers}

25 Considering that the surface chemical components of GE $\$ 2$

26 strongly affect the wettability to $\mathrm{LM}$ and $\mathrm{Li}^{+}$distribution, it i\$4

27 effective to introduce an interlayer between GE and LM, which5

28 has strong chemical binding energy with LM to ameliorate th 66

29 LM/GE interface. Specifically, Han and co-workers successfulty 8

30 introduced a $5 \mathrm{~nm}$ coating of $\mathrm{Al}_{2} \mathrm{O}_{3}$ on the $\mathrm{GE}$ by atomic layer 9

31 deposition (ALD). ${ }^{[38]}$ This vapor deposition method ensures the

32 rugged $\mathrm{GE}$ surface to be completely covered by $\mathrm{Al}_{2} \mathrm{O}_{3}$. The

33 subsequently heating induced formation of Li-Al alloy interfac 0

34 makes LM well wet GE along with significant decrease 1

35 interfacial ASR to $1 \Omega / \mathrm{cm}^{2}$ (Figure $5 \mathrm{a}-5 \mathrm{~b}$ ). After this, numerou $\$ 2$

36 materials that could be alloyed with LM have been employed $\$ 3$

37 wet the GE, such as $\mathrm{Si},{ }^{[39]} \mathrm{Mg},{ }^{[40]} \mathrm{Ge},{ }^{[41]} \mathrm{ZnO},{ }^{[42]} \mathrm{Ag},{ }^{[43]}$ and InO, ${ }^{[484}$

38 and most of these interlayers have been prepared through th 85

39 techniques like plasma-enhanced chemical vapor depositio\&6

40 (PECVD), ALD, magnetron sputtering (MS) and therm\&7

41 evaporation (TE). Note that these methods are relative 88

42 complicated, simple and easy strategies are still needed. 489

43 What's more, recent works showed that the alloy interlaye 0

44 underwent huge volume change during repeated1

45 alloying/dealloying processes, accompanied with the loss or 2

46 intimate contact between LM and GE, leading to the deterioratiog 3

47 of battery performance. ${ }^{[46]}$ In response, Feng et al. reported 94

$48 \mathrm{Cu}_{6} \mathrm{Sn}_{5}$ alloy interlayer with limited $\mathrm{Sn}$ diffusion and stable5

49 framework that could effectively mitigate the volume change 196

50 maintaining a good interface contact. ${ }^{[47]}$
Recently, adding ion conductors into alloy interlayers has been investigated to enable superior battery performance. ${ }^{[33]} \mathrm{A}$ new study from Sun's group designed a mixed conductive layer (MCL) by embedding electronic conductive $\mathrm{Cu}$ nanoparticles into $\mathrm{Li}_{3} \mathrm{~N}$ ionic conductive network through reacting the $\mathrm{Cu}_{3} \mathrm{~N}$ film with molten LM. ${ }^{[33]}$ The $\mathrm{Cu}$ nanoparticles provide homogenous electronic field, while the $\mathrm{Li}_{3} \mathrm{~N}$ matrix ensures fast $\mathrm{Li}^{+}$-conducting pathways (Figure $5 \mathrm{c}$ ). Benefiting from this synergy effect, the interfacial ASR reduced from $1138.5 \Omega / \mathrm{cm}^{2}$ to $83.4 \Omega / \mathrm{cm}^{2}$, and the CCD increased from $0.1 \mathrm{~mA} / \mathrm{cm}^{2}$ to $1.2 \mathrm{~mA} / \mathrm{cm}^{2}$ (Figure $5 \mathrm{~d}$ ). The CCD of GE with this MCL is higher than that of most GEs modified with pure alloy interlayers. Similarly, mixtures of alloys and $\mathrm{Li}_{2} \mathrm{O},{ }^{[48]} \mathrm{LiF}^{[49]}$ or $\mathrm{LiNbO}_{3}{ }^{[50]}$ have also played a positive role in reducing the interfacial ASR and increasing the CCD. However, using $\mathrm{Li}_{3} \mathrm{~N}$ alone as the interlayer gave rise to large interfacial ASR exceeding $160 \Omega / \mathrm{cm}^{2}$ even at $60{ }^{\circ} \mathrm{C}$, highlighting the importance of synergy effect of ion conductors and electron conductors. ${ }^{[11]}$
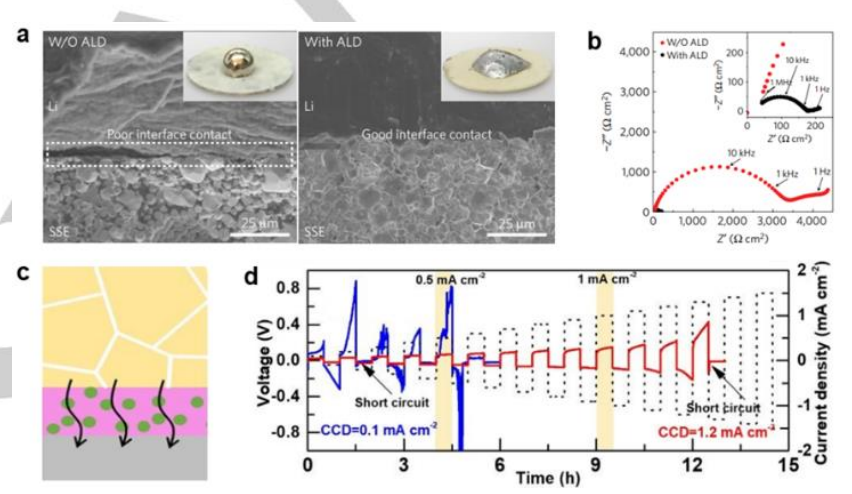

Figure 5. (a) SEM images of the GE/LM interface. Without $A L D-\mathrm{Al}_{2} \mathrm{O}_{3}$ coating, $\mathrm{GE}$ has poor contact with $\mathrm{LM}$ even after heating. With the help of $\mathrm{ALD}-\mathrm{Al}_{2} \mathrm{O}_{3}$ coating on GE, LM can uniformly bond with GE at the interface after heating. Inset are photos of melted LM on the surface of the GE, demonstrating classical wetting behavior for ALD-treated GE surface. ${ }^{[38]}$ (b) Comparison of EIS curves of the symmetric Li/Li cells with GEs. Inset shows the enlarged impedance curves of the ALD-treated GE cell. ${ }^{[38]}$ (c) Schematic of electric field distribution in MCL. Red, green, yellow and gray areas represent $\mathrm{Li}_{3} \mathrm{~N}$ matrix, $\mathrm{Cu}$ nanoparticle, GE and LM, respectively. ${ }^{[33]}$ (d) CCD of the symmetric Li/Li batteries with GE (blue curve) and the GE protected by MCL (red curve). ${ }^{[33]}$

There are many factors from alloy interlayers having pronounced effects on the battery performance, among which the composition of the alloy interlayers is a decisive factor towards interface properties. ${ }^{[52]}$ Very recently, Kim et al. observed different morphologies of Li deposition on the GEs modified with $\mathrm{Si} / \mathrm{Au} / \mathrm{Ag}$ layer. ${ }^{[24 c]}$ LM preferentially deposited at only a few sites and grew into whisker-shaped dendrite on Si layer. Although $\mathrm{Au}$ layer guided $\mathrm{Li}$ to precipitate with island-like shape, it failed to achieve uniform deposition. In sharp contrast, the Ag layer achieved a uniform Li deposition by providing numerous small nuclei. These distinguishing deposition behaviors might originate from the different solubilities of various metals in LM. The greater the solubility, the lower the energy barrier is required for LM nucleation and thus uniform LM deposition. In other words, the alloy interlayer is not only a buffer layer for Li redistribution, but also a matrix for facile Li precipitation.

Apart from the composition of the interlayers, the speed of $\mathrm{Li}^{+}$ transfer in the interlayer matrix, which strongly related to the crystallinity of the interlayers, is also an important factor towards 
1 interface properties. Unlike previous highly graphitized carbdo 0

2 (HGC) interlayers, low graphitized carbon (LGC) with amorphou $(81$

3 structure was recently reported to serve as an interlayer by Fer 62

4 et al. ${ }^{[53]}$ For $\mathrm{HGC}, \mathrm{Li}^{+}$could only transfer horizontally, while th 63

5 disordered structure of LGC provided many more $\mathrm{Li}^{+}$transf 64

6 pathways, resulting in faster lithiation speed of LGC than that 65

7 HGC. Besides, $\mathrm{Li}_{2} \mathrm{CO}_{3}$ contaminant disappeared by carbotherm 616

8 reduction $\left(\mathrm{Li}_{2} \mathrm{CO}_{3}+\mathrm{C} \rightarrow \mathrm{Li}_{2} \mathrm{O}+2 \mathrm{CO}\right)$ during the synthesis of LG67

9 through thermal-decomposition vapor deposition (TVD) metho $\$ 8$

10 Consequently, a low interfacial ASR of $9 \Omega / \mathrm{cm}^{2}$ and high CCD 69

$111.2 \mathrm{~mA} / \mathrm{cm}^{2}$ were achieved, which were the best results among0

12 the reported works with $\mathrm{Li}-\mathrm{C}$ alloy interlayers.

71

The physical properties of the alloy interlayers, such ak2

14 thickness and hardness, also need to be taken seriously in 3

15 fundamental research. As investigated by Chen et al., Si interlay $7 \mathrm{r} 4$

16 failed to maintain intimate contact with GE unless the thicknes755

17 was small than $180 \mathrm{~nm} \cdot{ }^{[54]}$ As the thickness increased, the battery6

18 performance continuously deteriorated, and only a few cyclez7

19 could be delivered when the thickness of Si layer close to $900 \mathrm{~nm} 7.8$

20 The above alloy interlayers can undoubtedly improve th? 9

21 interface contact and suppress the dendrite growth to some exte\&:0

22 but it is unfortunate that short circuit will still happen if the curreot1

23 density exceeds the CCD. To conquer this, Fu and co-worl\&2

24 proposed an intelligent interlayer to avoid short circuit by taking3

25 advantage of the conversion reaction between $\mathrm{MoS}_{2}$ and Li. 184

26 The concentrated current density near $\mathrm{Li}$ dendrite promoted th $\$ 5$

27 reaction between $\mathrm{MoS}_{2}$ and $\mathrm{Li}$ dendrite to generate $\mathrm{Li}_{2} \mathrm{~S} / \mathrm{Mo}$ lay\&6

28 with characterizations of poor electronic and $\mathrm{Li}^{+}$conductivity,

29 thereby suppressing the further growth of Li dendrite. Instead of

30 short circuit, obvious polarization up to $5 \mathrm{~V}$ occurred when the current density increased to $2.2 \mathrm{~mA} / \mathrm{cm}^{2}$.

From the above examples, it is obvious that the alloy interlayers can facilitate close contact with the GEs, thereby achieving low ASR. However, the severe volume expansion of the alloy interlayers during battery operation will rapidly deteriorate the interfacial contact, limiting the lifetime of the battery. Fine adjustments of the physical and chemical properties of the alloy interlayers are expected to alleviate this problem.

\subsection{Soft Interlayers}

Adding a minimal amount of OEs or gel polymer electrolytes (GPEs) between GE and LM can easily improve the interfacial contact. ${ }^{[56]}$ With a soft and bendable PVDF-HFP-based GPE interlayer, Liu et al. successfully decreased the interfacial ASR from $1.4 \times 10^{3}$ to $214 \Omega / \mathrm{cm}^{2}$. ${ }^{[56 a]}$ It should be noted that the absorbed OEs in GPEs still have security risks. Moreover, Bruce' group found LP30 $\left(\mathrm{LiPF}_{6}\right.$ in ethylene carbonate and dimethyl and a $\mathrm{Li}^{+}$-conducting solid electrolyte interlayer composed of $\mathrm{LiF}$, $\mathrm{Li}_{2} \mathrm{O}, \mathrm{Li}_{2} \mathrm{CO}_{3}$ and organic compositions was detected on the surface of LLZTO (Figure 6a). ${ }^{[57]}$ This made the interfacial ASR increase with time and finally stabilize at around $580 \Omega / \mathrm{cm}^{2}$ (Figure 6b), which was much higher than the combined resistance of LLZTO itself and Li/LLZTO interface. Accordingly, stabilizing 7 the OE/LLZTO interface is a primary prerequisite when adopting8 OEs or GPEs as interlayers. By adding n-BuLi, the interfacial AS\&9 of OE/GE interface almost kept constant during cycling 900 $\mathrm{LiFePO}_{4} / \mathrm{Li}$ battery, because $\mathrm{n}$-BuLi could not only suppres $\$ 1$ $\mathrm{Li}^{+} / \mathrm{H}^{+}$exchange, but also retard the formation of resistive 3 interlayer derived from by-reactions (Figure 6c). ${ }^{[58]}$ Up to now, the4 carbonate), a kind of commercial OE, was unstable with LLZTO evolutions of interfaces between various OEs and GEs are unclear and detailed researches are urgently needed. In addition, the interface stabilizers like n-BuLi deserve more attention.

PEs with excellent flexibility and relatively high safety have also been used as interlayers. For example, Duan et al. modified the GE surface with an ultrathin PEGMEA-based PE. ${ }^{[59]}$ Symmetric Li/Li battery with this modified GE delivered flat and stable voltage plateau for over $3200 \mathrm{~h}$ at a current density of 0.1 $\mathrm{mA} / \mathrm{cm}^{2}$ without discerned Li dendrite formation. Unfortunately, most GEs-based batteries with PEs interlayers have to operate above $50{ }^{\circ} \mathrm{C}$ due to the unsatisfactory room-temperature ionic conductivity and poor adhesive ability of PEs. ${ }^{[60]}$ Recently, Dong et al. developed a PIN@SN polymer glue, which was liquid at room temperature and could be solidified after "post curing stage", to behave as conformal caulking agent for LM/LLZTO interface (Figure $6 \mathrm{~d}$ ). ${ }^{[61]}$ Meanwhile, this polymer glue exhibited high peeloff strength $(70-90 \mathrm{~N} / \mathrm{cm})$ and good ionic conductivity at room temperature $\left(1.15 \times 10^{-4} \mathrm{~S} / \mathrm{cm}\right)$. Given these advantages, the interfacial ASR of LM/LLZTO interface reduced from 5114 to 104 $\Omega / \mathrm{cm}^{2}$ and the symmetric Li/Li battery cycled stably for up to 300 $\mathrm{h}$ at room temperature (Figure 6e). Generally, the PEs not only show lower ionic conductivities than that of the GEs, but also possess narrower electrochemical stability windows. This will undoubtedly sacrifice the advantages of the GEs-based ASSLMBs. In consideration of this dilemma, composite solid electrolytes which combine the merits of PEs and GEs are regarded as strong candidates.
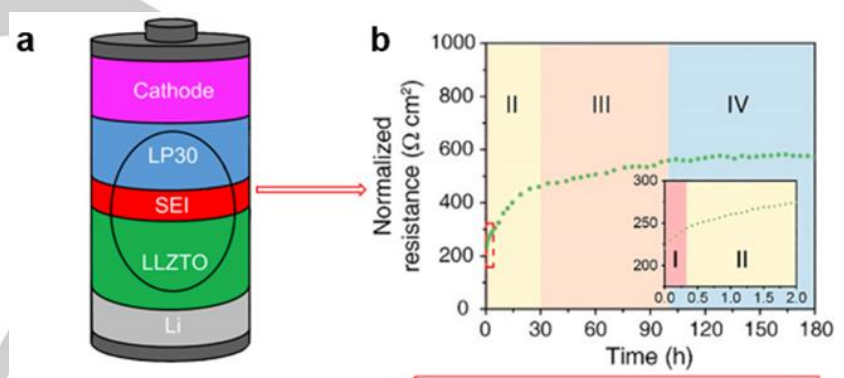

C

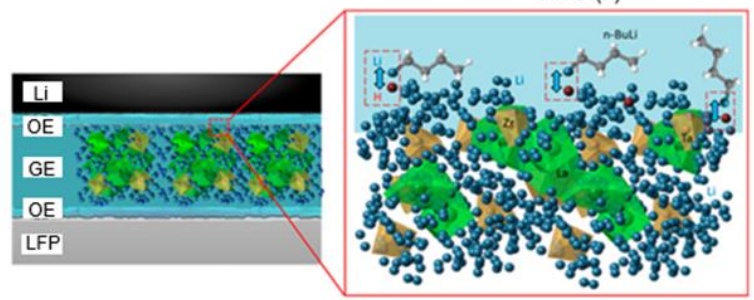

d

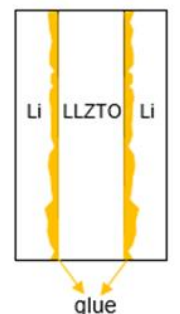

e

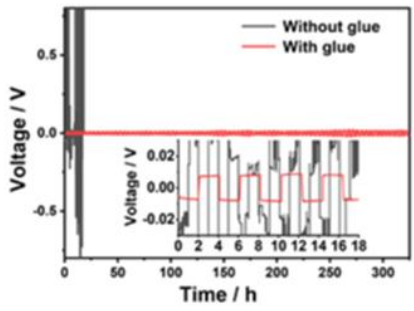

Figure 6. (a) Schematic of battery contains LLZTO/LP30 interface. ${ }^{[57]}$ (b) Interfacial ASR of the LLZTO/LP30 interface with time. According to different trends, the time dependence is categorized into four regions, I, II, III, and IV. ${ }^{[57]}$ (c) Illustration of the effect of n-BuLi on stabilizing the OE/GE interface. ${ }^{[58]}$ (d) Schematic diagram of LLZTO-based symmetric $\mathrm{Li} / \mathrm{Li}$ battery with glue interlayer. ${ }^{[61]}$ (e) Voltage profiles of the LLZTO-based symmetric Li/Li battery with and without glue interlayer (current densities: $0.05 \mathrm{~mA} / \mathrm{cm}^{2}$ ). ${ }^{[61]}$ 
In order to intuitively compare the strategies used for2 preparing the interlayers in sections 3.2 and 3.3 , their advantage $\$ 3$ and disadvantages are listed in Table 1 . It is clear that each technique more or less has some problems. More work should be 4 done to conquer these to further improve the battery performance 5 or make the technique with application prospect.

7 Table 1. Summary of the strategies for preparing the interlayers.

\begin{tabular}{|c|c|c|c|c|}
\hline Strategy & Technique & & Advantages & Disadvantages \\
\hline Deposition & $\begin{array}{l}\text { MS, ALD, } \\
\text { PECVD }\end{array}$ & TVD, & $\begin{array}{l}\text { Precise } \\
\text { controllability } \\
\text { and large- } \\
\text { scale } \\
\text { production }\end{array}$ & Complicated \\
\hline
\end{tabular}

Wet Reduction of metal Cheap and chemical ions fast method manufacturing Unmanageable 55 and easy to 56 produce by- 57
Physical Mechanical grinding and spraying

Facile products

\section{8}

59 Generate uneven 60 and connection between

Others

In-situ polymerization, blade casting and spinning
Good Cumbersome interlayer and GE 63

50
64 7f). ${ }^{[72]}$ This SLMA kept liquid throughout a wide temperature range

\section{3.4. Design of Metal Anodes}

9 Generally, alloying elements are normally added to adjust the 70 10 viscosity and surface energy of the liquid metals to decrease the 1 11 contact angle with ceramic substrates in the field of brazing 2 12 Instead of LM, molten Li-Sn alloy, ${ }^{[62]} \mathrm{Li}$-Al alloy ${ }^{[63]}$ and Li-C alloy ${ }^{[64]}$ 13 all exhibited reduced contact angles $\left(<90^{\circ}\right)$ toward GEs without 14 compromised ductility. These Li alloy/GE/Li alloy cells delivered 15 interfacial ASR as low as $1 \Omega / \mathrm{cm}^{2}$ and endured a high CCD up to $161 \mathrm{~mA} / \mathrm{cm}^{2}$. Interestingly, although the alloys experienced 17 significant volume changes, the interfaces between GEs and 18 alloys were more stable than that with LMs. Notably, Hu's group workers conducted in-depth studies on the liquid LM/GE interface (Figure 7e). ${ }^{[71]}$ In their studies, the ion conductivity of GE remarkably enhanced and the ASR of liquid LM/GE interface was smaller than $0.4 \Omega / \mathrm{cm}^{2}$. However, the high temperature for keeping LM in liquid state is energy-consuming and corrosive. In a later research, $\mathrm{Li}$ et al. demonstrated a semiliquid LM anode (SLMA) by dispersing in-situ generated Li microparticles in electron/ion dual-conductive liquid polymer composite (Figure

means of tape casting, a GE skeleton with porous-dense-porous trilayer structure was developed by Wachsman et al. ${ }^{70 a]}$ The porous layers acted as electrode supports and enlarged the interfacial surface area by more than forty times than the conventional 2D plane interface. Symmetric cell with LM filled into the pores of the porous layer successfully cycled up to $10 \mathrm{~mA} / \mathrm{cm}^{2}$ with interfacial ASR of 2-10 $\Omega / \mathrm{cm}^{2}$ (Figure $7 b-7 d$ ). Meanwhile, the large volume changes of LM could be accommodated by the porous skeleton of GE. It should be warned that although symmetric cell with this 3D electrode can operate normally at high current density, this is just due to the increased surface area. The CCD per unit area is not greatly improved.

Besides, operating batteries above the melting point of $L M$ is from $25^{\circ} \mathrm{C}$ to $150{ }^{\circ} \mathrm{C}$ and facilitated large-scale preparation. Owing to the intimate and conformal interfacial contact (Figure 7g), GE-based symmetric cell with the SLMA achieved stable voltage profile with overpotential about $150 \mathrm{mV}$ at a current density of 1 $\mathrm{mA} / \mathrm{cm}^{2}$ with $1 \mathrm{~h}$ half cycle time for nearly $400 \mathrm{~h}$. However, the SLMA-based cell was cycled above room temperature $\left(50^{\circ} \mathrm{C}\right)$ probably due to the slow $\mathrm{Li}^{+}$transfer of the SLMA. Changing the PEO-based ion-conductive polymer to another one with superior $\mathrm{Li}^{+}$transfer ability at room temperature may conquer this issue.

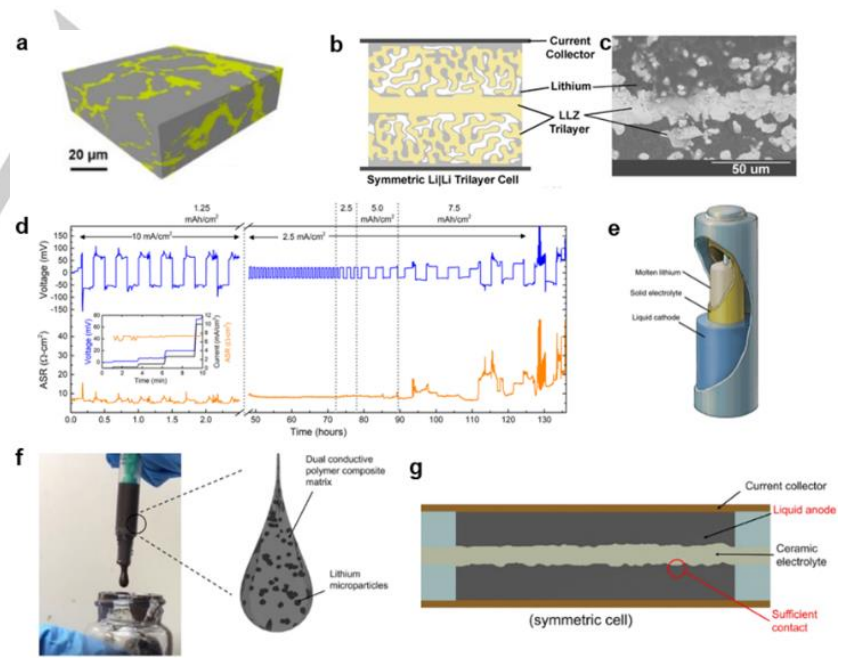

Figure 7. (a) $3 \mathrm{D}$ rendering image of the $\mathrm{Li}_{3} \mathrm{~N}$ added $\mathrm{Li}-\mathrm{C}$ alloy. Yellow and gray areas represent $L M$ and reacted $g-C_{3} \mathrm{~N}_{4}$, respectively. ${ }^{[66]}$ (b) Diagram of trilayer symmetric Li/Li battery. ${ }^{[70 a]}$ (c) SEM image of trilayer GE with two porous layers filled with LM. $^{[70 a]}$ (d) Voltage profiles (blue) and interfacial ASR (orange) response of trilayer symmetric Li/Li battery during battery operation. ${ }^{\text {[70a] }}$ (e) Schematic of battery contains liquid LM/GE interface. ${ }^{[71 \mathrm{~b}]}$ (f) Digital picture and schematic diagram of SLMA. ${ }^{[73]}$ (g) Schematic illustration of symmetric SLMA/SLMA cell with GE. ${ }^{73]}$

\subsection{Changes of GEs}


WILEY-VCH

1 According to previous works, the physical and chemical

2 properties of the GEs themselves deeply influence the

3 characteristics of the LM/GE interface, so changing the GEs is

4 promising to improve the interface. Adjusting the doping

5 elements, ${ }^{[29 a, 74]}$ downsizing to ultrafine powders, ${ }^{[75]}$ optimizing the

6 sintering process, ${ }^{[76]}$ adding sintering aids, ${ }^{[29 b,}{ }^{77]}$ and applying

7 advanced sintering technologies ${ }^{[78]}$ are favorable methods to

8 enhance the chemical/electrochemical stabilities of GEs and

9 reduce $\mathrm{Li}_{2} \mathrm{CO}_{3}$ impurity. For example, the introduction of just 2

10 wt.\% hydrophobic LiF into LLZT (LLZT-2LiF) could effectively

11 suppress $\mathrm{Li}_{2} \mathrm{CO}_{3}$ formation in air (Figure 8a), demonstrating a

12 significant decrease of interfacial ASR from 1260 to $35 \Omega / \mathrm{cm}^{2}$

13 (Figure 8b). ${ }^{[79]}$ Unfortunately, the LiF additive not only reduced the

14 density but also worsened the ionic conductivity of LLZT. Guo's

15 group put forward another interesting strategy by creating a $\mathrm{Li}$ -

16 deficient shield on the surface of GE after calcinated it at

$17900{ }^{\circ} \mathrm{C} .{ }^{[80]}$ This Li-deficient shield was capable of restraining the

18 formation of $\mathrm{Li}_{2} \mathrm{CO}_{3}$, and thus $\mathrm{Li}_{2} \mathrm{CO}_{3}$-free $\mathrm{GE}$ could be obtained

19 after removing the shield. As a result, a low interfacial ASR of 495

$20 \Omega / \mathrm{cm}^{2}$ was achieved. Although these methods successful\$5 6

21 suppress the formation of $\mathrm{Li}_{2} \mathrm{CO}_{3}$, the ionic conductivities of th 57

22 GEs all decrease, which will limit the $\mathrm{Li}^{+}$transfer at high rate

23 operation.
Besides, reducing the electronic conductivities of the GEs is also an effective approach to improve the CCD. Song et al. coated the $\mathrm{Li}_{7} \mathrm{La}_{2.75} \mathrm{Ca}_{0.25} \mathrm{Zr}_{1.75} \mathrm{Nb}_{0.25} \mathrm{O}_{12}$ (LLCZN) powder with lowelectronic-conductivity $\mathrm{LiAlO}_{2}$ by a simple chemical coating 1 process (Figure $8 \mathrm{c}$ ). ${ }^{\left[{ }^{11 a]}\right]}$ The electronic conductivity of the LiAIO ${ }_{22}$ coated LLCZN $\left(1.01 \times 10^{-8} \mathrm{~S} / \mathrm{cm}\right)$ was almost three times lower 3 than that of LLCZN without $\mathrm{LiAlO}_{2}$ layer $\left(3.59 \times 10^{-8} \mathrm{~S} / \mathrm{cm}\right)$, which 3 significantly slowed the Li dendrite growth. Moreover, the LiAIO25 coated LLCZN exhibited much lower interfacial ASR and higher 5 $\operatorname{CCD}\left(25 \Omega / \mathrm{cm}^{2} ; 0.75 \mathrm{~mA} / \mathrm{cm}^{2}\right)$ compared with those of pure LLCZN $\left(4100 \Omega / \mathrm{cm}^{2} ; 0.4 \mathrm{~mA} / \mathrm{cm}^{2}\right)$. This method improves the CCD just by reducing the electronic conductivities of the graung boundaries. If the electronic conductivities of the grains can be reduced at the same time, a greater breakthrough is expected. 7

As important as avoiding the formation of $\mathrm{Li}$ dendrite, delaying the propagation of the $\mathrm{Li}$ dendrite that has alread $/ 3$ formed is also an effective strategy to prolong the battery life. As 4 illustrated in Figure 8d, Xu et al. engineered the grain boundaries of LLZT by introduction of $\mathrm{Li}_{3} \mathrm{PO}_{4}$ as a self-limiting sintering aid. ${ }^{8} 4 \mathrm{~T}$ The $\mathrm{Li}_{3} \mathrm{PO}_{4}$ additive was sufficient to prevent $\mathrm{Li}$ dendrite from 76 propagating the LLZT, because $\mathrm{Li}_{3} \mathrm{PO}_{4}$ was capable of in-sity 7 reacting with $\mathrm{Li}$ dendrite formed at grain boundaries. Most recentl 8 Zhang's group coated and infused $\mathrm{GE}$ with $\mathrm{Li}_{3} \mathrm{PO}_{4}$ thorough $\mathrm{AL} / \mathrm{O}$ $\mathrm{Li}_{3} \mathrm{PO}_{4}$ was $\mathrm{Li}^{+}$-conductive but $\mathrm{e}$-insulating, which effective 1 suppressed the growth of $\mathrm{Li}$ dendrites and the direct reduction of 3 the GE by LM, achieving a low ASR of $1 \Omega / \mathrm{cm}^{2}$ and a high CC 84 of $2.2 \mathrm{~mA} / \mathrm{cm}^{2}$. So, modifying the grain boundaries of $\mathrm{GE}$ and the interface between LM and GE at the same time is hopeful achieve a long-lasting stabilization effect.
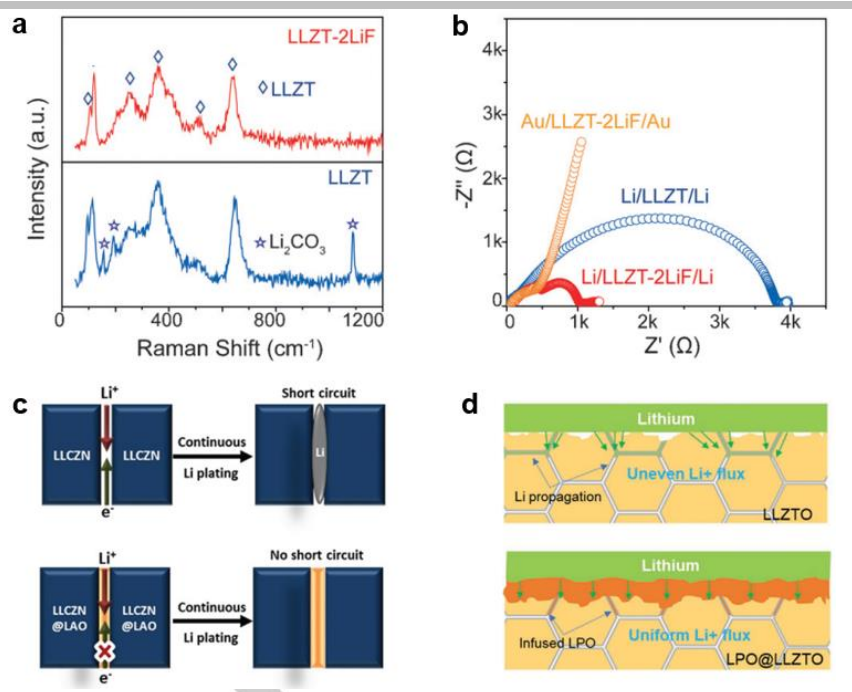

d

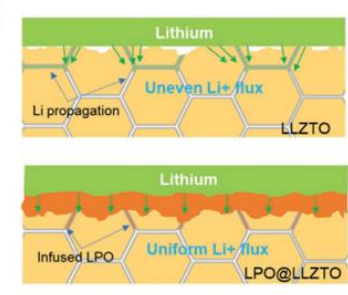

Figure 8. (a) Raman spectra of LLZT and LLZT-2LiF after exposed to air for two weeks. ${ }^{[79]}$ (b) EIS spectra of LLZT-2LiF and LLZT with Li electrodes. ${ }^{[79]}$ (c) Schematic illustrations of $\mathrm{Li}$ dendrite formation within LLCZN and principle of suppressing it by means of surface coating. ${ }^{[31 \mathrm{a}]}$ (d) Schematic of Li dendrite suppression by coating and infusing GE with $\mathrm{Li}_{3} \mathrm{PO}_{4}{ }^{[82]}$

\section{Summary and Outlook}

The attractive properties of GEs, such as high ion conductivity, excellent stability against LM as well as wide electrochemical potential window, make them one of the most promising candidates for ASSLMBs. After decades of development, significant progress has been achieved in GEs-based ASSLMBs. However, as the GEs-based ASSLMBs are still in infancy, the current GEs-based ASSLMBs are always faced with various challenges, including but not limited to unsatisfactory LM/GE interface. In this minireview, we discussed the existing two main problems of the LM/GE interface and summarized the corresponding solutions (Table 2). Moreover, on this basis, some perspectives are proposed as follows:

(1) Since the challenges of LM/GE interface and their origins are often interrelated, most of the existing approaches, which focus only on one of the problems of LM/GE interface, are far from achieving a favourable LM/GE interface. A comprehensive solution that can bring unexpected performance improvements is in crying need. In addition, it will be more instructive to study the LM/GE interface in a full cell than in a symmetrical cell.

(2) Current research results have proved that the death of ASSLMBs is closely related to the interface failure during battery operation. Although researchers have conducted detailed studies on the LM/GE interfaces of freshly assembled ASSLMBs, the evolution of the interfaces during charging and discharging is still unclear. In addition, the LM/GE interface evolution in ASSLMBs is undoubtedly different when matched with various cathode materials (Li-contained oxides, sulfur, and $\mathrm{O}_{2}$ etc.) Therefore, in operando and in situ characterizations with suitable battery

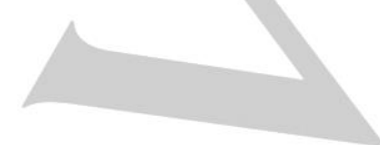
models should be developed for getting precise information during battery operation.

(3) Despite there are many solutions that can effectively reduce the interfacial ASR and increase the CCD, the detailed mechanism cannot be clearly unveiled based on experimental data alone. Simulation methods are essential for understanding the underlying reasons, and further providing theoretical guidance 
WILEY-VCH

1 for future studies. Moreover, pre-screening with simulations

2 before the experiment can greatly improve research efficiency 3 and avoid unnecessary waste.

(4) From a practical point of view, the costs of interfacial

7 consideration. For example, most of the metal or nonmetal

8 reagents required to synthesize the alloy interlayers and the

9 supporting devices like ALD are expensive, and the process is

10 time-consuming. But, ALD can accurately control the thickness to

11 get nanometer-scale interlayer, and facilitate large-scale

12 manufacturing which is beneficial for reducing cost. Notably, up tp8

13 now, all the proposed strategies can only be performed at a

14 laboratory level due to the low yield and harsh conditions. For

15 long-term development, great efforts focused on this issue areg

16 highly required.

17 Table 2. Summary of the ASR and CCD values of recently reported works. 2

\begin{tabular}{|c|c|c|c|c|}
\hline Strategy & Specific plan & $\begin{array}{l}\text { ASR } \\
\left(\Omega / \mathrm{cm}^{2}\right)\end{array}$ & $\begin{array}{l}\mathrm{CCD} \\
\left(\mathrm{mA} / \mathrm{cm}^{2}\right)\end{array}$ & Reference 23 \\
\hline Removal & Reacting & 28 & - & 34 \\
\hline
\end{tabular}

$\begin{array}{lll}\mathrm{Li}_{2} \mathrm{CO}_{3} & \text { with carbon } & 26 \\ & & \end{array}$

Removal of Heating GE 178

$\mathrm{Li}_{2} \mathrm{CO}_{3}$

35

Removal of $\mathrm{HCl}$ treatment $\quad 26$

$\mathrm{Li}_{2} \mathrm{CO}_{3}$

36

Removal of $\mathrm{H}_{3} \mathrm{PO}_{4}$ treatment 7

$\mathrm{Li}_{2} \mathrm{CO}_{3}$

0.8

$\begin{array}{lll}\begin{array}{l}\text { Alloy } \\ \text { interlayers }\end{array} & \mathrm{Al}_{2} \mathrm{O}_{3} & 1 \\ \text { Alloy } & \mathrm{Cu}_{6} \mathrm{Sn}_{5} & 236\end{array}$

$\begin{array}{lll}\begin{array}{l}\text { Alloy } \\ \text { interlayers }\end{array} & \mathrm{Cu}_{6} \mathrm{Sn}_{5} & 236 \\ \text { Alloy } & \mathrm{Cu} / \mathrm{Li}_{3} \mathrm{~N} & 83.4\end{array}$

$\begin{array}{lll}\begin{array}{l}\text { Alloy } \\ \text { interlayers }\end{array} & \mathrm{Cu} / \mathrm{Li}_{3} \mathrm{~N} & 83.4\end{array}$

1.2

$\begin{array}{ll}\text { Alloy } & \text { Low graphitized } 9 \\ \text { interlayers } & \\ \text { carbon }\end{array}$

$\begin{array}{lll}\text { Alloy } & \mathrm{MoS}_{2} & 14 \\ \text { interlayers } & \end{array}$

Soft PVDF-HFP-

interlayers based GPE

interlayers

Soft

interlayers

LP30 liquid 580

electrolyte PIN@SN 104

metal

anodes

Design of $\mathrm{Li}_{3} \mathrm{~N}$ added $\mathrm{Li}-\mathrm{C} \quad 11 \quad 1.5$

66

anodes

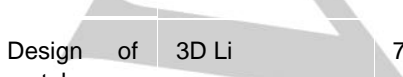

metal

anodes

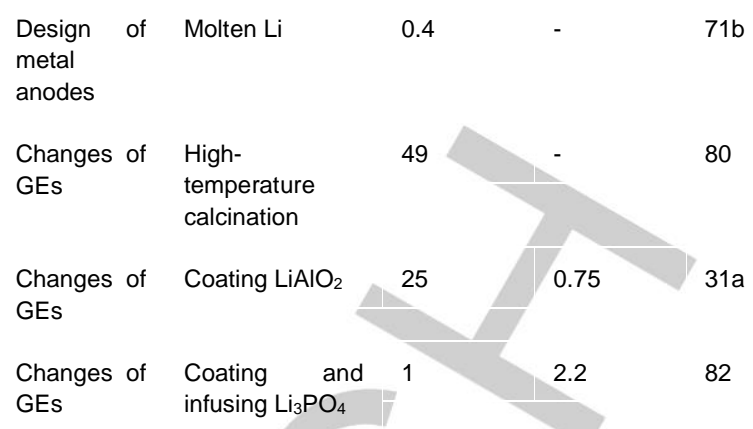

0.4

$71 b$

metal

anodes

Changes of High-

GEs temperature

calcination

Changes of Coating $\mathrm{LiAlO}_{2}$

GEs

$\begin{array}{llll}\text { Changes of } & \begin{array}{l}\text { Coating and } \\ \text { infusing } \mathrm{Li}_{3} \mathrm{PO}_{4}\end{array} & 2.2 & 82\end{array}$

\section{Acknowledgements}

20 This work was financially supported by the National Key R\&D Program of China (2017YFA0206700 and 2016YFB0100103), the National Natural Science Foundation of China (21725103), the K. C. Wong Education Foundation (GJTD-2018-09), the Jilin Province Capital Construction Funds Project (2020C026-1), and Changchun Science and Technology Development Plan Funding Project (19SS010).

27 Keywords: dendrite $\cdot$ garnet electrolyte $\bullet$ interface $\cdot$ Li metal $•$

28 resistance $\cdot$ solid-state electrolyte

29 [1] C. Wang, A. Wang, L. Ren, X. Guan, D. Wang, A. Dong, C. Zhang, G. Li, J. Luo, Adv. Funct. Mater. 2019, 29, 1905940.

[2] A. Manthiram, X. Yu, S. Wang, Nat. Rev. Mater. 2017, 2, 16103.

[3] T. Famprikis, P. Canepa, J. A. Dawson, M. S. Islam, C. Masquelier, Nat. Mater. 2019, 18, 1278-1291.

[4] X. Wang, R. Kerr, F. Chen, N. Goujon, J. M. Pringle, D. Mecerreyes, M. Forsyth, P. C. Howlett, Adv. Mater., DOI: 10.1002/adma.201905219.

[5] a) R. Murugan, V. Thangadurai, W. Weppner, Angew. Chem. Int. Ed. 2007, 46, 7778-7781; b) C. Ma, Y. Cheng, K. Yin, J. Luo, A. Sharafi, J. Sakamoto, J. Li, K. L. More, N. J. Dudney, M. Chi, Nano Lett. 2016, 16, 7030-7036; c) Q. Liu, Z. Geng, C. Han, Y. Fu, S. Li, Y. He, F. Kang, B. Li, J. Power Sources 2018, 389, 120-134.

[6] a) X. Huang, Y. Lu, H. Guo, Z. Song, T. Xiu, M. E. Badding, Z. Wen, ACS Appl. Energy Mater. 2018, 1, 5355-5365; b) S. Narayanan, F. Ramezanipour, V. Thangadurai, Inorg. Chem. 2015, 54, 6968-6977; c) G. Han, B. Kinzer, R. Garcia-Mendez, H. Choe, J. Wolfenstine, J. Sakamoto, J. Eur. Ceram. Soc. 2020, 40, 1999-2006.

[7] A. J. Samson, K. Hofstetter, S. Bag, V. Thangadurai, Energy Environ. Sci. 2019, 12, 2957-2975.

[8] Z. Shen, W. Zhang, G. Zhu, Y. Huang, Q. Feng, Y. Lu, Small Methods 2019, 4, 1900592.

[9] F. Han, Y. Zhu, X. He, Y. Mo, C. Wang, Adv. Energy Mater. 2016, 6, 1501590.

[10] Y. Zhu, J. G. Connell, S. Tepavcevic, P. Zapol, R. Garcia - Mendez, N. J. Taylor, J. Sakamoto, B. J. Ingram, L. A. Curtiss, J. W. Freeland, D. D. Fong, N. M. Markovic, Adv. Energy Mater. 2019, 9, 1803440.

[11] H. Zheng, S. Wu, R. Tian, Z. Xu, H. Zhu, H. Duan, H. Liu, Adv. Funct. Mater. 2019, 30, 1906189.

[12] L. Cheng, E. J. Crumlin, W. Chen, R. Qiao, H. Hou, F. S. Lux, V. Zorba R. Russo, R. Kostecki, Z. Liu, K. Persson, W. Yang, J. Cabana, T. Richardson, G. Chen, M. Doeff, Phys. Chem. Chem. Phys. 2014, 16, 18294-18300.

[13] A. Sharafi, S. Yu, M. Naguib, M. Lee, C. Ma, H. M. Meyer, J. Nanda, M. Chi, D. J. Siegel, J. Sakamoto, J. Mater. Chem. A 2017, 5, 13475-13487.

[14] W. Xia, B. Xu, H. Duan, X. Tang, Y. Guo, H. Kang, H. Li, H. Liu, J. Am. Ceram. Soc. 2017, 100, 2832-2839.

[15] a) Y. Jin, P. J. McGinn, J. Power Sources 2013, 239, 326-331; b) R. H. 
Brugge, A. K. O. Hekselman, A. Cavallaro, F. M. Pesci, R. J. Chater, J. A.0 Kilner, A. Aguadero, Chem. Mater. 2018, 30, 3704-3713.

[16] W. Xia, B. Xu, H. Duan, Y. Guo, H. Kang, H. Li, H. Liu, ACS Appl. Mater. Interfaces 2016, 8, 5335-5342.

[17] C. Monroe, J. Newman, J. Electrochem. Soc. 2005, 152, A396-A404. 74

[18] S. Yu, R. D. Schmidt, R. Garcia-Mendez, E. Herbert, N. J. Dudney, J. B.5 Wolfenstine, J. Sakamoto, D. J. Siegel, Chem. Mater. 2015, 28, 197-20ð6.6

[19] a) C. Wang, Y. Gong, J. Dai, L. Zhang, H. Xie, G. Pastel, B. Liu, B.7 9 Wachsman, H. Wang, L. Hu, J. Am. Chem. Soc. 2017, 139, 14257-142648 b) R. Raj, J. Wolfenstine, J. Power Sources 2017, 343, 119-126; c) S. YZ,9 D. J. Siegel, ACS Appl. Mater. Interfaces 2018, 10, 38151-38158. 80 [20] M. J. Wang, R. Choudhury, J. Sakamoto, Joule 2019, 3, 2165-2178. 81

[21] T. Krauskopf, H. Hartmann, W. G. Zeier, J. Janek, ACS Appl. Mat\&. 2 Interfaces 2019, 11, 14463-14477.

[22] a) W. S. LePage, Y. Chen, E. Kazyak, K.-H. Chen, A. J. Sanchez, A. P 84 E. M. Arruda, M. D. Thouless, N. P. Dasgupta, J. Electrochem. Soc. 2018,5 166, A89-A97; b) T. Krauskopf, B. Mogwitz, C. Rosenbach, W. G. Zeiæ,6 J. Janek, Adv. Energy Mater. 2019, 9, 1902568; c) A. Sharafi, H. 87 Meyer, J. Nanda, J. Wolfenstine, J. Sakamoto, J. Power Sources 2018,8 302, 135-139.

[23] T. Krauskopf, R. Dippel, H. Hartmann, K. Peppler, B. Mogwitz, F. 9.0 Richter, W. G. Zeier, J. Janek, Joule 2019, 3, 2030-2049.

[24] a) W. Manalastas, J. Rikarte, R. J. Chater, R. Brugge, A. Aguadero, 92.2 Buannic, A. Llordés, F. Aguesse, J. Kilner, J. Power Sources 2019, 419,3 287-293; b) L. Porz, T. Swamy, B. W. Sheldon, D. Rettenwander, 9.4 Frömling, H. L. Thaman, S. Berendts, R. Uecker, W. C. Carter, Y.-19.5 Chiang, Adv. Energy Mater. 2017, 7, 1701003; c) S. Kim, C. Jung, H. Kin, 6 K. E. Thomas - Alyea, G. Yoon, B. Kim, M. E. Badding, Z. Song, J. ChanQ,7 J. Kim, D. Im, K. Kang, Adv. Energy Mater., DQ9:8 10.1002/aenm.201903993.

[25] G. Bucci, J. Christensen, J. Power Sources 2019, 441, 227186.

[26] Y.Ren, Y. Shen, Y Lin, C.W. Nan, ACS Appl. Mater. Interfaces 2019101 5928-5937.

[27] E. J. Cheng, A. Sharafi, J. Sakamoto, Electrochim. Acta 2017, 223, B6-3 91.

[28] C. L. Tsai, V. Roddatis, C. V. Chandran, Q. Ma, S. Uhlenbruck, M. Br 1040,5 P. Heitjans, O. Guillon, ACS Appl. Mater. Interfaces 2016, 8, 106106 10626.

[29] a) B. Dong, S. R. Yeandel, P. Goddard, P. R. Slater, Chem. Mater. 2d10,8 32, 215-223; b) Z. Zhang, A. R. Gonzalez, K. L. Choy, ACS Appl. Endrgy 9 Mater. 2019, 2, 7438-7448.

[30] S. Smetaczek, A. Wachter-Welzl, R. Wagner, D. Rettenwander,1d.1 Amthauer, L. Andrejs, S. Taibl, A. Limbeck, J. Fleig, J. Mater. Chenl 1 2 2019, 7, 6818-6831.

[31] a) Y. Song, L. Yang, W. Zhao, Z. Wang, Y. Zhao, Z. Wang, Q. ZhaolH.4 Liu, F. Pan, Adv. Energy Mater. 2019, 9, 1900671; b) F. Aguesse,1W.5 Manalastas, L. Buannic, J. M. L. D. Amo, G. Singh, A. Llordes, J. Kilhel,6 ACS Appl. Mater. Interfaces 2017, 9, 3808-3816; c) Y. Ren, Y. Shen 1.7 Lin, C.-W. Nan, Electrochem. Commun. 2015, 57, 27-30.

118

[32] H.-K. Tian, B. Xu, Y. Qi, J. Power Sources 2018, 392, 79-86. 119

[33] H. Huo, Y. Chen, R. Li, N. Zhao, J. Luo, J. G. P. D. Silva, R. Mückel Z2 0 Kaghazchi, X. Guo, X. Sun, Energy Environ. Sci. 2020, 13,127-134.121

[34] Y. Li, X. Chen, A. Dolocan, Z. Cui, S. Xin, L. Xue, H. Xu, K. Park, J1 Z22 Goodenough, J. Am. Chem. Soc. 2018, 140, 6448-6455. 123

[35] L. Cheng, M. Liu, A. Mehta, H. Xin, F. Lin, K. Persson, G. Chen, E1 24 Crumlin, M. Doeff, ACS Appl. Energy Mater. 2018, 1, 7244-7252. 125

[36] H. Huo, Y. Chen, N. Zhao, X. Lin, J. Luo, X. Yang, Y. Liu, X. Guo, X. Slu2, 6 Nano Energy 2019, 61, 119-125.

[37] Y. Ruan, Y. Lu, X. Huang, J. Su, C. Sun, J. Jin, Z. Wen, J. Mater. Ch 128 A 2019, 7, 14565-14574.

[38] X. Han, Y. Gong, K. K. Fu, X. He, G. T. Hitz, J. Dai, A. Pearse, B. Liul B.0 Wang, G. Rubloff, Y. Mo, V. Thangadurai, E. D. Wachsman, L. Hu, Nla3.1 Mater. 2017, 16, 572-579.

[39] W. Luo, Y. Gong, Y. Zhu, K. K. Fu, J. Dai, S. D. Lacey, C. Wang, B. Liß3,3 X. Han, Y. Mo, E. D. Wachsman, L. Hu, J. Am. Chem. Soc. 2016, 133,4 12258-12262.

[40] K. K. Fu, Y. Gong, Z. Fu, H. Xie, Y. Yao, B. Liu, M. Carter, E. Wachsmba, 6 L. Hu, Angew. Chem. Int. Ed. 2017, 56, 14942-14947.

[41] W. Luo, Y. Gong, Y. Zhu, Y. Li, Y. Yao, Y. Zhang, K. K. Fu, G. Pastel, d. B.8
Lin, Y. Mo, E. D. Wachsman, L. Hu, Adv. Mater. 2017, 29, 1606042

[42] C. Wang, Y. Gong, B. Liu, K. Fu, Y. Yao, E. Hitz, Y. Li, J. Dai, S. Xu, W. Luo, E. D. Wachsman, L. Hu, Nano Lett. 2017, 17, 565-571.

[43] W. Feng, X. Dong, P. Li, Y. Wang, Y. Xia, J. Power Sources 2019, 419, 91-98.

[44] J. Lou, G. Wang, Y. Xia, C. Liang, H. Huang, Y. Gan, X. Tao, J. Zhang, W. Zhang, J. Power Sources 2020, 448, 227440

[45] a) Y. Shao, H. Wang, Z. Gong, D. Wang, B. Zheng, J. Zhu, Y. Lu, Y.-S. $\mathrm{Hu}, \mathrm{X}$. Guo, H. Li, X. Huang, Y. Yang, C.-W. Nan, L. Chen, ACS Energy Lett. 2018, 3, 1212-1218; b) C. Zhou, A. J. Samson, K. Hofstetter, V Thangadurai, Sustainable Energy Fuels 2018, 2, 2165-2170; c) M. Cai, Y. Lu, J. Su, Y. Ruan, C. Chen, B. V. R. Chowdari, Z. Wen, ACS Appl. Mater. Interfaces 2019, 11, 35030-35038; d) B. Sun, Y. Jin, J. Lang, K. Liu, M. Fang, H. Wu, Chem. Commun. 2019, 55, 6704-6707.

[46] a) M. He, Z. Cui, C. Chen, Y. Li, X. Guo, J. Mater. Chem. A 2018, 6 , 11463-11470; b) H. Koshikawa, S. Matsuda, K. Kamiya, M. Miyayama, Y. Kubo, K. Uosaki, K. Hashimoto, S. Nakanishi, J. Electroanal. Chem. 2019, 835, 143-149.

[47] W. Feng, X. Dong, Z. Lai, X. Zhang, Y. Wang, C. Wang, J. Luo, Y. Xia, ACS Energy Lett. 2019, 4, 1725-1731.

[48] a) K. Liu, R. Zhang, M. Wu, H. Jiang, T. Zhao, J. Power Sources 2019 433, 226691; b) Y. Chen, M. He, N. Zhao, J. Fu, H. Huo, T. Zhang, Y. Li, F. Xu, X. Guo, J. Power Sources 2019, 420, 15-21.

[49] B. Hu, W. Yu, B. Xu, X. Zhang, T. Liu, Y. Shen, Y. H. Lin, C. W. Nan, L. Li, ACS Appl. Mater. Interfaces 2019, 11, 34939-34947.

[50] G. V. Alexander, M. S. Indu, S. Kamakshy, R. Murugan, Electrochim. Acta 2020, 332, 135511.

[51] H. Xu, Y. Li, A. Zhou, N. Wu, S. Xin, Z. Li, J. B. Goodenough, Nano Lett. 2018, 18, 7414-7418.

[52] N. Zhao, R. Fang, M.-H. He, C. Chen, Y.-Q. Li, Z.-J. Bi, X.-X. Guo, Rare Met. 2018, 37, 473-479.

[53] W. Feng, X. Dong, X. Zhang, Z. Lai, P. Li, C. Wang, Y. Wang, Y. Xia, Angew. Chem. Int. Ed. 2020, 59, 5346-5349.

[54] C. Chen, Q. Li, Y. Li, Z. Cui, X. Guo, H. Li, ACS Appl. Mater. Interfaces 2018, 10, 2185-2190.

[55] J. Fu, P. Yu, N. Zhang, G. Ren, S. Zheng, W. Huang, X. Long, H. Li, X Liu, Energy Environ. Sci. 2019, 12, 1404-1412.

[56] a) B. Liu, Y. Gong, K. Fu, X. Han, Y. Yao, G. Pastel, C. Yang, H. Xie, E. D. Wachsman, L. Hu, ACS Appl. Mater. Interfaces 2017, 9, 18809-18815; b) J. Wang, Y. Yin, T. Liu, X. Yang, Z. Chang, X. Zhang, Nano Res. 2018, 11, 3434-3441.

[57] J. Liu, X. Gao, G. O. Hartley, G. J. Rees, C. Gong, F. H. Richter, J. Janek, Y. Xia, A. W. Robertson, L. R. Johnson, P. G. Bruce, Joule 2020, 4, 101 108.

[58] B. Xu, H. Duan, H. Liu, C. A. Wang, S. Zhong, ACS Appl. Mater Interfaces 2017, 9, 21077-21082

[59] H. Duan, Y. X. Yin, Y. Shi, P. F. Wang, X. D. Zhang, C. P. Yang, J. L. Shi R. Wen, Y. G. Guo, L. J. Wan, J. Am. Chem. Soc. 2018, 140, 82-85.

[60] a) L. Chen, Z. Huang, W. Pang, Z. Jin, Y. Li, C.-A. Wang, Electrochim Acta 2020, 330, 135352; b) S. A. Pervez, P. Ganjeh - Anzabi, U. Farooq M. Trifkovic, E. P. L. Roberts, V. Thangadurai, Adv. Mater. Interfaces 2019, 6, 1900186; c) H. Huo, Y. Chen, J. Luo, X. Yang, X. Guo, X. Sun Adv. Energy Mater. 2019, 9, 1804004.

[61] D. Dong, B. Zhou, Y. Sun, H. Zhang, G. Zhong, Q. Dong, F. Fu, H. Qian, Z. Lin, D. Lu, Y. Shen, J. Wu, L. Chen, H. Chen, Nano Lett. 2019, 19 2343-2349.

[62] C. Wang, H. Xie, L. Zhang, Y. Gong, G. Pastel, J. Dai, B. Liu, E. D. Wachsman, L. Hu, Adv. Energy Mater. 2018, 8, 1701963.

[63] Y. Lu, X. Huang, Y. Ruan, Q. Wang, R. Kun, J. Yang, Z. Wen, J. Mater. Chem. A 2018, 6, 18853-18858.

[64] J. Duan, W. Wu, A. M. Nolan, T. Wang, J. Wen, C. Hu, Y. Mo, W. Luo, Y. Huang, Adv. Mater. 2019, 31, e1807243.

[65] C. Yang, H. Xie, W. Ping, K. Fu, B. Liu, J. Rao, J. Dai, C. Wang, G. Pastel, L. Hu, Adv. Mater. 2019, 31, e1804815.

[66] Y. Huang, B. Chen, J. Duan, F. Yang, T. Wang, Z. Wang, W. Yang, C. Hu, W. Luo, Y. Huang, Angew. Chem. Int. Ed. 2020, 59, 3699-3704.

[67] G. Ferraresi, S. Uhlenbruck, C. L. Tsai, P. Novák, C. Villevieille, Batteries Supercaps, DOI: 10.1002/batt.201900173.

[68] S. Afyon, K. V. Kravchyk, S. Wang, J. v. d. Broek, C. Hänsel, M. V. 


\section{MINIREVIEW}

Kovalenko, J. L. M. Rupp, J. Mater. Chem. A 2019, 7, 21299-21308.

[69] G. Ferraresi, M. E. Kazzi, L. Czornomaz, C.-L. Tsai, S. Uhlenbruck, C. Villevieille, ACS Energy Lett. 2018, 3, 1006-1012.

[70] a) G. T. Hitz, D. W. McOwen, L. Zhang, Z. Ma, Z. Fu, Y. Wen, Y. Gong, J. Dai, T. R. Hamann, L. Hu, E. D. Wachsman, Mater. Today 2019, 22, 5057; b) D. W. McOwen, S. Xu, Y. Gong, Y. Wen, G. L. Godbey, J. E. Gritton, T. R. Hamann, J. Dai, G. T. Hitz, L. Hu, E. D. Wachsman, Adv. Mater. 2018, 30, e1707132; c) C. Yang, L. Zhang, B. Liu, S. Xu, T. Hamann, D. McOwen, J. Dai, W. Luo, Y. Gong, E. D. Wachsman, L. Hu, Proc. Natl. Acad. Sci. USA 2018, 115, 3770-3775.

[71] a) Y. Jin, K. Liu, J. Lang, X. Jiang, Z. Zheng, Q. Su, Z. Huang, Y. Long, C. Wang, H. Wu, Y. Cui, Joule 2020, 4, 262-274; b) Y. Jin, K. Liu, J. Lang, D. Zhuo, Z. Huang, C. A. Wang, H. Wu, Y. Cui, Nat. Energy 2018, 3, 732738.

[72] C.-Z. Zhao, Q. Zhang, Joule 2019, 3, 1575-1577.

[73] S. Li, H. Wang, J. Cuthbert, T. Liu, J. F. Whitacre, K. Matyjaszewski, Joule 2019, 3, 1637-1646.

[74] a) J. Gai, E. Zhao, F. Ma, D. Sun, X. Ma, Y. Jin, Q. Wu, Y. Cui, J. Eur. Ceram. Soc. 2018, 38, 1673-1678; b) Federico M. Pesci, R. H. Brugge, A. K. O. Hekselman, A. Cavallaro, R. J. Chater, A. Aguadero, J. Mater. Chem. A 2018, 6, 19817-19827.

[75] a) M. Yi, T. Liu, X. Wang, J. Li, C. Wang, Y. Mo, Ceram. Int. 2019, 45, 786-792; b) X. Zeng, A. J. Martinolich, K. A. See, K. T. Faber, J. Energy Storage 2020, 27, 101128.

[76] a) J. Su, X. Huang, Z. Song, T. Xiu, M. E. Badding, J. Jin, Z. Wen, Ceram. Int. 2019, 45, 14991-14996; b) M. B. Dixit, M. Regala, F. Shen, X. Xiao, K. B. Hatzell, ACS Appl. Mater. Interfaces 2019, 11, 2022-2030.

[77] a) H. Xie, C. Li, W. H. Kan, M. Avdeev, C. Zhu, Z. Zhao, X. Chu, D. Mu F. Wu, J. Mater. Chem. A 2019, 7, 20633-20639; b) W. Zhang, C. Sun, J. Phys. Chem. Solids 2019, 135, 109080; c) R. H. Basappa, T. Ito, T. Morimura, R. Bekarevich, K. Mitsuishi, H. Yamada, J. Power Sources 2017, 363, 145-152.

[78] S. P. Kammampata, R. H. Basappa, T. Ito, H. Yamada, V. Thangadurai, ACS Appl. Energy Mater. 2019, 2, 1765-1773.

[79] Y. Li, B. Xu, H. Xu, H. Duan, X. Lu, S. Xin, W. Zhou, L. Xue, G. Fu, A. Manthiram, J. B. Goodenough, Angew. Chem. Int. Ed. 2017, 56, 753-756.

[80] J. F. Wu, B. W. Pu, D. Wang, S. Q. Shi, N. Zhao, X. Guo, X. Guo, ACS Appl. Mater. Interfaces 2019, 11, 898-905.

[81] B. Xu, W. Li, H. Duan, H. Wang, Y. Guo, H. Li, H. Liu, J. Power Sources 2017, 354, 68-73.

[82] T. Deng, X. Ji, Y. Zhao, L. S. Cao, S. Li, S. Hwang, C. Luo, P. F. Wang H. P. Jia, X. L. Fan, X. C. Lu, D. Su, X. L. Sun, C. S. Wang, J. G. Zhang, Adv. Mater., DOI: 10.1002/adma.202000030.
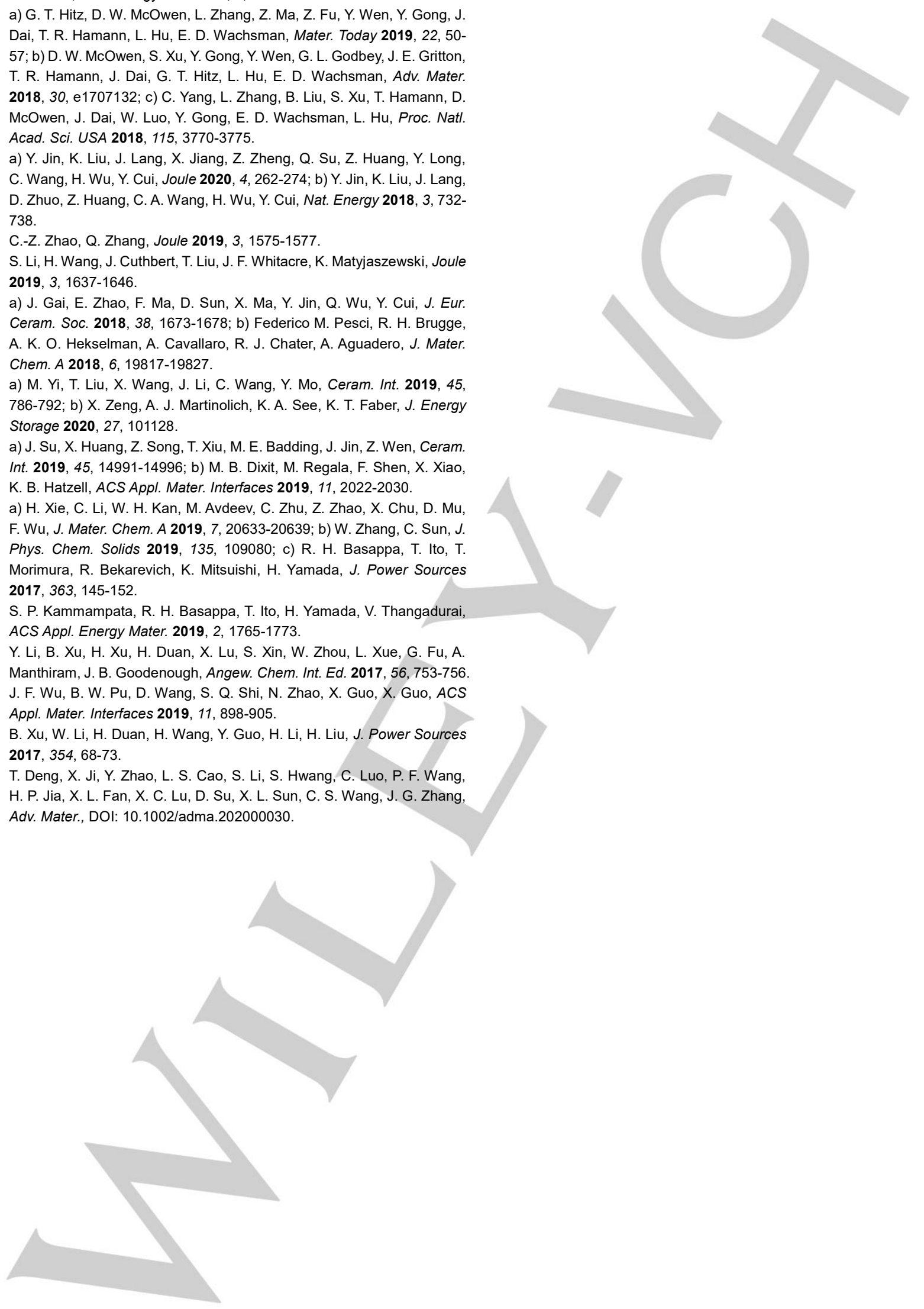


\section{Entry for the Table of Contents}

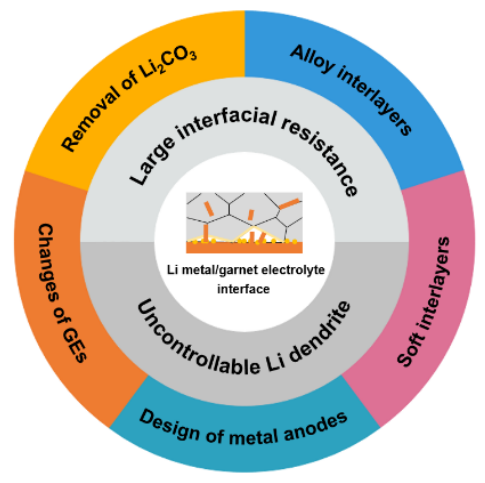

Unsatisfactory lithium metal/garnet electrolyte (LM/GE) interface largely deteriorates the performance of all-solid-state lithium metal batteries (ASSLMBs). This minireview introduces the development of GEs-based ASSLMBs and summarizes the challenges of the LM/GE interface. Accordingly, strategies for improving the LM/GE interface have been discussed with the perspectives for future research. 